\title{
The World Stress Map
}

\begin{abstract}
Knowledge of the stress field in the Earth's crust is a key issue for the understanding of geodynamic processes, seismic hazard assessment, and stability of underground openings such as waste disposals, tunnels, mines or wells, and reservoir management. The World Stress Map project is a collaborative project of academia, industry and governmental organizations that aims to understand the states and sources of tectonic stresses in the Earth's crust. We present the World Stress Map at 1:46,000,000 scale as a result of more than two decades of international collaboration. The map reveals that the first-order pattern of stress is of plate-wide scale, indicating that plate boundary forces are the major control of the stress orientations and the tectonic regime.
\end{abstract}

\section{The World Stress Map project}

The World Stress Map (WSM) was published in April 2007 by the Commission of the Geological Map of the World. It displays the tectonic regime and the orientation of the contemporary maximum horizontal compressional stress $\left(\mathrm{S}_{\mathrm{H}}\right)$ of more than 12,000 stress data records within the Earth's crust incorporating the WSM database release 2005 (Reinecker et al., 2005). The map is a Mercator projection at 1:46,000,000 scale, including topography and bathymetry from Smith and Sandwell (1997) and plate boundary configuration from the global plate model PB2002 (Bird, 2003).

The goal of the WSM project is the development and compilation of the extensive, quality-ranked stress database with a focus on determining the orientation of $\mathrm{S}_{\mathrm{H}}$ in the Earth's crust. However, the database also contains relative and absolute stress magnitudes and additional information about each data point (such as depth, date, reference of the original work). The initial phase of the WSM project was within the International Lithosphere Program (ILP) from 1986-1992, led by Mary Lou Zoback in co-operation with more than 30 scientists worldwide. Since 1995, the WSM has been a project of the Heidelberg Academy of Sciences and Humanities, based at the Geophysical Institute of University of Karlsruhe, Germany. The WSM is a public-domain project that provides all of its data, software and additional services free of charge (available online at www.world-stress-map.org).

The 2005 release of the WSM database contains 15,969 stress data records with stress indicators interpreted from a range of methods within the upper $40 \mathrm{~km}$ of the lithosphere.

The past WSM releases gave insight into large-scale patterns of regional stress orientations, i.e., the first-order stress patterns due to plate boundary forces, and second-order patterns due to topography, large lateral density variations, and deglaciation effects (Zoback, 1992). However, in addition to further defining broad-scale stress patterns, the WSM 2005 database release has developed some regions of high data resolution that enable the user to investigate variations in stress orientations on local scales and to discuss factors controlling third-order stress patterns such as active faults, local inclusions, detachment horizons, and density contrasts. These forces act as a major control on the stress field orientations when the magnitudes of the horizontal stresses are close to isotropic (Heidbach et al., 2007; Tingay et al., 2005).

The database contains a wide range of stress indicators such as hydraulic fracturing from which under ideal conditions the full stress tensor can be determined and focal mechanism solutions that deliver the orientation of the three principal stress axes and the tectonic regime, i.e., the relative magnitudes of $\mathrm{S}_{\mathrm{H}}, \mathrm{S}_{\mathrm{h}}$ (minimum horizontal compressional stress), and $\mathrm{S}_{\mathrm{v}}$ (vertical stress). The minimum stress information needed for each data record is the $\mathrm{S}_{\mathrm{H}}$ orientation. Thus, mapping of the WSM database is proceeded by plotting the $\mathrm{S}_{\mathrm{H}}$ orientation and the tectonic regime, even though a large number of data records in the database provide more stress information.

\section{Methods for determining stress orientations}

The present-day stress information presented in the WSM is estimated from a variety of stress indicators of four categories: earthquake focal mechanism solutions, stress-induced borehole breakouts, in-situ stress measurements and geologic indicators. Each technique reflects the stress field of different rock volumes ranging from $10^{-3}$ to $10^{9} \mathrm{~m}^{3}$ and different depths ranging from near surface down to $40 \mathrm{~km}$ depth. Within the upper $6 \mathrm{~km}$ of the Earth's crust the stress field is mapped by a wide range of methods with borehole breakouts as a major contributor. Below $\sim 6 \mathrm{~km}$ depth focal mechanism solutions are the only stress indicators available, except a few deep scientific drilling projects. In order to avoid data that are mainly controlled by topography the minimum depth for stress data incorporated in the WSM database is $100 \mathrm{~m}$.

\section{Focal mechanism solutions}

The majority of stress data in the WSM database is derived from earthquake focal mechanism solutions $(77 \%)$. The radiation pattern of seismic wave from an earthquake allows us to construct a focal mechanism that consists of two perpendicular planes: the fault plane and the auxiliary plane. They divide the volume into compressional and extensional quadrants. The orientation of these planes determine the orientation of the compressional (P), intermediate (B), and extensional $(\mathrm{T})$ axes. These principal strain axes are used as proxies for the orientation of the principal stresses axes $\sigma_{1}, \sigma_{2}$, and $\sigma_{3}$, but due to the uncertainties of this first-order approximation the quality of the stress orientations derived from focal mechanism solutions is restricted to C-quality data (i.e., a deviation of up to $\pm 25^{\circ}$ is assumed). Furthermore, when a focal mechanism solution is located in the vicinity of a plate boundary, and the kinematics of the focal mechanism solution is similar to the plate boundary kinematics, the event is omitted and flagged as a Possible Plate Boundary Event indicating that the P-, B-, and T-axis of the focal mechanism solution might predominantly reflect the geometry and kinematics of the plate boundary, rather than the orientation of the regional stress field. Stress orientation from a group of focal mechanism solutions (or geologic fault-slip data), determined with stress inversion methods, are also included in the database.

\section{Borehole breakouts}

Borehole breakouts are stress-induced elongations of the wellbore cross-section and are formed when the circumferential stress concentration at the wellbore wall exceeds the stress required to cause compressive failure of the formation. The elongation of the wellbore cross-section is the result of compressive shear failure on intersecting conjugate planes. In vertical boreholes the maximum stress at the borehole wall occurs perpendicular to $\mathrm{S}_{\mathrm{H}}$. Similar to these borehole breakouts drilling-induced tensile fractures are caused by tensile failure of the borehole wall and form when the wellbore stress concentration is less than the tensile strength of the rock. Drilling-induced tensile fractures form parallel to the $\mathrm{S}_{\mathrm{H}}$ orientation in vertical boreholes. Borehole breakouts are interpreted from oriented four- or six-arm caliper log data (e.g., the High-Resolution Dipmeter Tool) or from acoustic or resistivity image logs (e.g., Formation Micro Imager, Simultaneous Acoustic and Resistivity Imager). 


\section{In-situ stress measurements}

Hydraulic fracturing is analog to the drilling-induced tensile fractures, but here the fractures are artificially induced by pressurizing an isolated section of a borehole until a tensile fracture occurs. Overcoring is a stress relief measurement that is quite common in mines and civil engineering projects. Here the deformation (elastic relaxation) of a small rock specimen $\left(\mathrm{a}\right.$ few $\mathrm{cm}^{3}$ ) is measured after its removal from ambient rock. With the knowledge of the elastic rock properties the stress tensor is derived. Both methods have the potential-under ideal conditions - that the full stress tensor can be deduced.

\section{Geologic indicators}

The estimation of stress orientations from geological indicators for the WSM database is restricted to young data, i.e., from Quaternary age. There is two major geological stress indicators: igneous dikes and volcanic alignments and fault-slip analysis. Analog to the hydraulic fracture, igneous dikes and volcanic alignments grow in the plane of the $\mathrm{S}_{\mathrm{H}}$ orientation. In the fault-slip analysis striae or slickensides on fault planes are used. To receive a stable stress inversion for the principal stress orientations and their relative magnitudes, a sufficiently high number of slip directions from faults with different orientations at a given local side is required (Sperner et al., 2003).

\section{Quality-ranking of the data}

The success of the WSM is based on a standardized quality ranking scheme for the individual stress indicators making them comparable on a global scale. The quality ranking scheme was introduced by Zoback and Zoback (1991; 1989), and refined and extended by Sperner et al. (2003). It is internationally accepted and guarantees reliability and global comparability of the stress data. Each stress data record is assigned a quality between $\mathrm{A}$ and $\mathrm{D}$, with $\mathrm{A}$ being the highest quality and $\mathrm{D}$ the lowest. A-quality means that the $\mathrm{S}_{\mathrm{H}}$ orientation is accurate to within $\pm 15^{\circ}$, B-quality to within $\pm 20^{\circ}$, C-quality to within $\pm 25^{\circ}$, and D-quality to within $\pm 40^{\circ}$. For most methods these quality classes are defined through standard deviation of $\mathrm{S}_{\mathrm{H}}$. For example, an A-quality stress orientation estimate from borehole breakouts requires the observation of at least 10 consistently oriented breakouts (with a standard deviation $<12^{\circ}$ ) in a single borehole with a total breakout length of over $300 \mathrm{~m}$. Furthermore, the quality ranking of all stress indicators facilitates the comparison of stress data determined from different methods and depths. In general, A, B, and $\mathrm{C}$ quality stress indicators are considered reliable for use in analyzing stress patterns and the interpretation of geodynamic processes.

\section{The World Stress Map services}

The website of the WSM project is equipped with the easy-touse database interface CASMO (Create A Stress Map Online) for the custom building of individual stress maps by simply selecting the region of interest, stress indicator type, depth range, and quality of the stress data (Heidbach et al., 2004). In addition, users can add their own stress data to this plot. The return time for a CASMO request is less than a minute and the stress map is delivered via email (Heidbach and Höhne, 2007). Alternatively the user can install the offline software CASMI (Create A Stress Map Interactively). CASMI is a public domain program running under Unix-like operating systems based on GMT (Wessel and Smith, 1995). It has a graphical user interface and specific features needed to visualize the WSM data. CASMI includes the WSM 2005 database release and will be sent free of charge after registration at the project's web site (http://www.world-stress-map.org/casmi).

\section{Digital data}

The CD-ROM of the WSM has five sections: (1) Global stress map in a layered pdf format; (2) WSM database release 2005 in three different formats (*.xls, *.csv, *.dbf); (3) Bibliography of the WSM 2005 database release with 1593 references. It is given in two formats: A raw text file with the references listed in alphabetical order of the abbreviation given in the data record fields REF1-REF4 and in the format of the bibliography software Endnote ${ }^{\circledR}$; (4) Visualization tool CASMI; (5) Website of the WSM that contains all information on the project and technical details of the database.

\section{Discussion and conclusion}

The WSM project provides fundamental insights into the firstand second-order crustal stress pattern on plate-wide and regional scales larger than $500 \mathrm{~km}$ as well as on the forces controlling them. The $\mathrm{S}_{\mathrm{H}}$ orientation in North America, South America and Europe are, at the plate-wide scale, predominately sub-parallel to absolute or relative plate motions. This correlation of $\mathrm{S}_{\mathrm{H}}$ orientation and plate motion suggests that the first-order intraplate stress patterns are the result of the same forces that drive plate motion, in particular ridge push, slab pull, trench suction, collisional forces, and traction at the base of the lithosphere (Hillis and Reynolds, 2000; Müller et al., 1992; Richardson, 1992; Zoback, 1992). Second-order stress patterns at $100-500 \mathrm{~km}$ scales indicate that lateral density contrasts due to continental rifting, isostatic compensation and topography, deglaciation effects, as well as lithospheric flexure have an additional impact on regional-scale stress fields.

Some regions of the map provide high data density that enables us to investigate third-order stress pattern and its sources at smaller scales due to active faults, local inclusions, detachment horizons, and density contrasts. Some of these regions (e.g., northern Germany) with high data density exhibit stress rotations with respect to the plate-wide and regional stress orientation (Heidbach et al., 2007; Tingay et al., 2006).

\section{Perspectives of the WSM project}

The progress in understanding the contemporary stress pattern in the last two decades has only been possible due to the ongoing systematic compilation of stress data with international collaboration. Even though the WSM project will end as a project of the Heidelberg Academy of Sciences and Humanities by the end of 2008, we will continue our work. From 2009 onwards, the project will be maintained and further developed at the GeoForschungsZentrum (GFZ) Potsdam, Germany. However, the future success of the WSM is nevertheless dependent on the assistance of the scientific community. We thus call for active participation in the further development of the WSM database release regardless of which type of support: new stress data, the analysis of the stress field of a specific region, or discussions on new stress determination methods.

\section{Acknowledgements}

The World Stress Map project is a collaborative project that would not be possible without the effort of many scientists worldwide. We are indebted to numerous individual researchers and working groups all over the world for providing stress data. The complete list of contributors is too numerous to be given herein. However, the authors are particularly grateful for major contributions for the WSM 2005 database release by Richard Hillis and Scott Reynolds of the Australasian Stress Map project (University of Adelaide), Lourdes Colmenares (Stanford University), Philip Fleckenstein (Karlsruhe University), Mihaela Negut (PETROM, Bucarest), Paola Montone (INGV, Rome), Maria Teresa Mariucci (INGV, Rome), Mark Zoback (Stanford University), and John Townend (University of Wellington). We also thank the World Stress Map advisory board members Egon Althaus, John Cook, Roy Gabrielsen, Domenico Giardini, Helmut Kipphan, Onno Oncken, Chris Reigber, Markus Rothacher, and Mark Zoback for the longterm support. We especially want to express our thanks to Jean-Paul Cadet and Philippe Rossi from the Commission of the Geological Map of the World for the effort and enthusiasm they devoted to this project. 


\section{References}

Bird, P., 2003, An updated digital model for plate boundaries, Geochemistry. Geophysics. Geosystems, v. 4, no. 34, art. no. 1027, doi:10.1029/ $2001 \mathrm{GC} 000252$.

Heidbach, O., A. Barth, P. Connolly, F. Fuchs, B. Müller, J. Reinecker, B. Sperner, M. Tingay, and F. Wenzel, 2004, Stress Maps in a Minute: The 2004 World Stress Map Release, Eos Transactions, v. 85, pp. 521-529.

Heidbach, O., and J. Höhne, 2007, CASMI - a tool for the visualization of the World Stress Map data base, Computers and Geosciences, in press.

Heidbach, O., J. Reinecker, M. Tingay, B. Müller, B. Sperner, K. Fuchs, and F. Wenzel, 2007, Plate boundary forces are not enough: Secondand third-order stress patterns highlighted in the World Stress Map database, Tectonics, in press.

Hillis, R.R., and S.D. Reynolds, 2000, The Australian Stress Map, Journal Geological Society, v. 157, pp. 915-921.

Müller, B., M.L. Zoback, K. Fuchs, L. Mastin, S. Gregersen, N. Pavoni, O. Stephansson, and C. Ljunggren, 1992, Regional Patterns of Tectonic Stress in Europe, Journal Geophysical Research, v. 97, pp. 11783-11803.

Reinecker, J., O. Heidbach, M. Tingay, B. Sperner, and B. Müller, 2005, The 2005 release of the World Stress Map (available online at www.world-stress-map.org).

Richardson, R.M., 1992, Ridge Forces, Absolute Plate Motions, and the Intraplate Stress Field, Journal Geophysical Research, v. 97, pp. $11739-11748$

Smith, W.H.F., and D.T. Sandwell, 1997, Global Sea Floor Topography from Satellite Altimetry and Ship Depth Soundings, Science, v. 277, pp. 1956-1962.

Sperner, B., B. Müller, O. Heidbach, D. Delvaux, J. Reinecker, and K. Fuchs, 2003, Tectonic stress in the Earth's crust: advances in the World Stress Map project, in D.A. Nieuwland, ed., New insights in structural interpretation and modelling, Special Publication Series, v. 212, Geological Society, London, pp. 101-116.

Tingay, M., B. Müller, J. Reinecker, O. Heidbach, F. Wenzel, and Fleckenstein.P., 2005, The World Stress Map Project 'Present-day Stress in Sedimentary Basins' initiative: building a valuable public resource to understand tectonic stress in the oil patch, The Leading Edge, v. 24, pp. 1276-1282.

Tingay, M.R.P., B. Müller, J. Reinecker, and O. Heidbach; 2006, State and Origin of the Present-day Stress Field in Sedimentary Basins: New Results from the World Stress Map Project, 41st U.S. Symposium on Rock Mechanics (USRMS): "50 Years of Rock Mechanics-Landmarks and Future Challenges.", Golden, Colorado, June 17-21, 2006, pp. $1-14$.

Wessel, P., and W.H.F. Smith, 1995, New version of Generic Mapping Tools Released, Eos Transactions, v. 76, p. 329

Zoback, M.L., and M.D. Zoback, 1989, Tectonic stress field of the conterminous United States, in L.C. Pakiser and W.D. Mooney, eds., Geophysical Framework of the Continental United States, v. 172, Geological Society America Memoir, Boulder, Colorado, pp. 523-539.

Zoback, M.D., and M.L. Zoback, 1991, Tectonic stress field of North America and relative plate motions, in D.B. Slemmons, E.R. Engdahl, M.D. Zoback', and D.D. Blackwell, eds., Neotectonics of North America, Decade Map, v. I, Geological Society of America, Boulder, Colorado, pp. 339-366.

Zoback, M.L. 1992, First and second order patterns of stress in the lithosphere: The World Stress Map Project, Journal of Geophysical Research, v. 97, no. B8, pp. 11703-11728.

\section{Relevant web site}

World Stress Map Project

http://www.world-stress-map.org

\section{To order}

\section{World Stress Map}

Mercator Projection

Equatorial scale: 1 : 46,000,000

Total surface of the map: $120 \times 545 \mathrm{~cm}$

(C) CCGM \& Heidelberg Academy of Sciences and Humanities 2007

Price: 15.00 Euros including CD-ROM

To order this map: www.ccgm.org - ccgm@club-internet.fr

\section{Oliver Heidbach}

Geophysical Institute

Karlsruhe University

Hertzstr. 16

76187 Karlsruhe

Germany

Karl Fuchs, Birgit Müller \& Friedemann Wenzel

Geophysical Institute

Karlsruhe University

Hertzstr. 16

76187 Karlsruhe

Germany

Heidelberg Academy of Sciences and Humanities

Karlst. 4

69117 Heidelberg

Germany

John Reinecker

Institute of Geosciences

University of Tübingen

Sigwartstrasse 10,

72076 Tübingen

Germany

\section{Mark Tingay}

School of Earth \& Environmental Sciences

DP313 Mawson Building

University of Adelaide SA 5005

Australia

\section{Blanka Sperner}

Geological Institute

TU Bergakademie Freiberg

Bernhard-von-Cotta-Str. 2

09599 Freiberg

Germany 


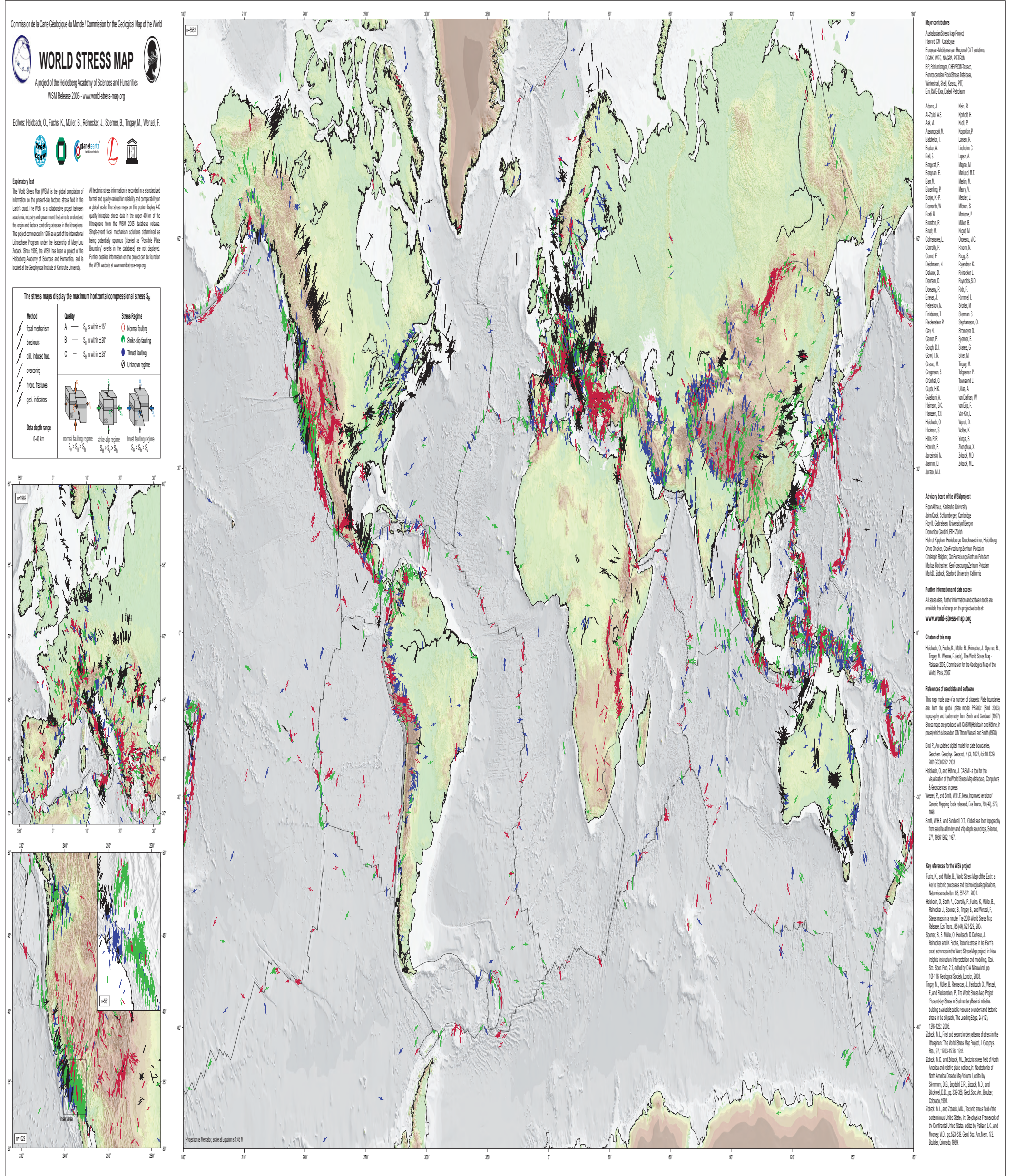

